\title{
UNIVERSITYOF
}

FORWARD

THINKING

WESTMINSTER用

WestminsterResearch

http://www.westminster.ac.uk/westminsterresearch

Modelling and forecasting international interest rate spreads: UK, Germany, Japan and the US

Gough, O., Nowman, K.B. and Van Dellen, S.

This is an author's accepted manuscript of an article published in the International Journal of Financial Engineering and Risk Management, 1 (4), pp. 309-333, 2014. The final definitive version is available online at:

https://dx.doi.org/10.1504/IJFERM.2014.065648

The WestminsterResearch online digital archive at the University of Westminster aims to make the research output of the University available to a wider audience. Copyright and Moral Rights remain with the authors and/or copyright owners.

Whilst further distribution of specific materials from within this archive is forbidden, you may freely distribute the URL of WestminsterResearch: ((http://westminsterresearch.wmin.ac.uk/)).

In case of abuse or copyright appearing without permission e-mail repository@westminster.ac.uk 


\title{
Modelling and Forecasting International Interest Rate Spreads: UK, Germany, Japan and the US
}

\author{
Orla Gough, K. Ben Nowman* and Stefan Van Dellen \\ Department of Accounting, Finance and Governance, Westminster Business School, 35 \\ Marylebone Road, London NW1 5 LS, U.K \\ E-mail: Gougho@wmin.ac.uk \\ Email: Nowmank@wmin.ac.uk \\ Email: $\underline{\text { S.Vandellen@wmin.ac.uk }}$ \\ *Corresponding author
}

\begin{abstract}
The interest rate spread is of importance to policy makers and finance professionals in asset allocation and is a common measure of financial market stress. In this paper we model and forecast the interest rate spreads for a number of countries using two well known continuous time models and discrete time ARMA and ARFIMA models. We use monthly and weekly data which covers the recent global financial market crisis of 2007-2009 for Germany, Japan, UK and the US. We find that the continuous time Merton model outperforms all other model specifications in terms of the mean of the forecast errors, MAPE and RMSE.
\end{abstract}

KEYWORDS: Continuous Time, Gaussian Estimation, ARMA, ARIMA, ARFIMA, Time Series, Spreads, Forecasting, International.

\section{Biographical notes:}

Professor Gough is Head of Department of Accounting, Finance and Governance.

Ben Nowman is Professor of Finance.

Dr Stefan Van Dellen is Senior Lecturer in Finance.

Acknowledgments: We thank the referees for substantial comments which helped us improve the paper. 


\section{Introduction}

The modelling and forecasting of interest rate spreads, or what is commonly refereed to as the term spread or yield curve slope, is of importance for central bankers and other market practitioners. Interest rate spreads are simply the difference between long term and short term rates. Interestingly a change from a positive to a negative interest rate spread would indicate that a recession is likely in the future (see below for a more detailed discussion on this). Furthermore, the interest rate spread can be used to forecast future short-term interest rates, where Campbell and Schiller (1987), Fama (1984, 1990) and Hardouvelis (1988), amongst many others, document that interest rate spreads can predict the correct direction of future changes in short rates. Finally, interest rate spreads are of particular use to traders in international financial markets who trade the slope of the yield curve and fund managers who use this for asset allocation purposes.

The past twenty years has seen the emergence of the use of the term spread ability to predict output growth and recessions as an important area of research, where Wheelock and Wohar (2009) provide an excellent recent survey of these literature. Studies on predicting output growth for example include, Laurent (1988), Harvey (1988, 1989), Estrelle and Hardouvelis (1991) provided some of the first empirical evidence on how interest rate spreads could be used to predict output growth in the US. This relation was confirmed by Shaaf (2000), Ang, Piazzesi, and Wei (2006), Aretz and Peel (2008) and Bordo and Haubrich (2008), although Bordo and Haubrich reported that spreads only improved forecast in three of the nine sub-periods studied. Looking at this relation in a more international context, Esrella, Rogrigues and Schich (2003), Duarte, Venetis and Paya (2005) and Nakaoto (2005) found similar results in Germany, the Euro area and Japan, respectively. 
Looking at a different application of interest rate spreads, Estrelle and Hardouvelis (1991) and Estrella and Mishkin (1998) demonstrated that the interest rate spread significantly outperforms other financial and macroeconomic variables in forecasting recessions in the US. This relation was again confirmed by Galvao (2006) and Rosenberg and Maurer (2008), while Bernard and Gerlach (1998) found a similar relation in eight industrialised countries. In Ivanova, Lahiri and Seitz (2000) they investigated the use of interest rate spreads as predictors of German inflation and business cycles. Interestingly, there is a relative dearth in the literature as to the best approach to model and forecast the interest rate spread itself. As a result, and to address this issue in this paper we look at a different aspect on spreads by modelling and forecasting international spreads using two different econometric modelling methodologies, one in continuous time and one in discrete time ${ }^{1}$.

The international markets we consider are the UK, US, Japan and Germany. In particular for the UK market or the Gilt market (gilt-edged) is where Treasury bills and bonds are regularly auctioned by the UK Debt Management Office (DMO) on behalf of HM Treasury. A review of the market is given in DMO (2012). In the US market the securities issued are termed Treasury bills, notes and bonds issued by the US Treasury Department (see, for example, Treasury Bulletin (2013)). The Japanese Ministry of Finance (MOF) sells various kinds of Japanese Government Bonds (JGB) to the market over the short-medium and long term. Short term are Treasury bills, medium-term usually about 5 years and long term 10 years and over. An excellent overview is given in Yoshino (2008). Lastly the market for German government securities which are issued by the Finance Agency is divided into the short end market and capital market instruments from three months to 30 years. In the short end issue we have Treasury bills called "Bubills". The other end of the market are Federal Treasury notes "Schaetze" with a maturity of two years, followed by five-year Federal notes "Bobls".

\footnotetext{
${ }^{1}$ Other approaches to modelling include, for example, discrete time cointegration analysis and the use of vector Autoregressive (VAR) or Factor (or Fractionally Integrating Factor) Vector Autoregressive models (FI-F-VAR) models.
} 
Lastly at the long end are Federal bonds "Bunds" with maturities of ten and 30 years. For Germany, Japan and the US we use as a proxy for the short end the 1-month interbank offered rate from the British Banking Association. The interbank rate represents the rate charged on short-term loans made between banks.

The modelling in continuous time in economics and finance has a long history. Bergstrom and Nowman (2007) provide a number of advantages of modelling in continuous time. The major problem with a continuous time model is that the data are only available at discrete time intervals. Thus a discretization of the continuous time model is needed. In this paper we use the discrete time model of Nowman (1997) (see Bergstrom and Nowman (2007)) for the estimation of the continuous time models. To estimate the parameters we use the general Gaussian estimation methods of Bergstrom (1983, 1990), Nowman (1997, 2001, 2003, 2006), Bergstrom and Nowman (2007) to estimate the well known continuous time models of Merton (1973) and Vasicek (1977).

We compare the forecasting performance of these models with the Autoregressive Integrated Moving Average (ARIMA) modelling of Box and Jenkins (1976) as well as the Autoregressive Fractionally Integrated Moving Average (ARFIMA) models, first proposed by Granger and Joyeux (1980), Granger (1980, 1981) and Hosking (1981), which have been developed and applied in forecasting time series. There is evidence in the literature of long memory in interest rates, where Shea (1991) found some evidence of long memory in interest rate spreads and Backus and Zin (1993) found evidence of long memory in interest rates using various time series. Supporting this argument, Crato and Rothman (1994) found similar results for bond yields when using the full maximum likelihood to estimate an $\operatorname{ARFIMA}(0 ; \mathrm{d} ; 1)$ model.

The rest of the paper is organized as follows: Section 2 outlines the continuous time models and discrete time models used. Section 3 presents the data and empirical results are given in 
Section 4. Forecasting performance is discussed in Section 5 and conclusions are presented in Section 6.

\section{Continuous and discrete time spread modelling}

We use the important continuous time interest rate models of Merton (1973) and Vasicek (1977) which have been widely used in financial markets in modelling the yield curve, bond pricing and options on bonds. The Vasicek (1977) model has the advantage of allowing for closed form solution of bond prices. It also incorporates the idea of mean reversion which incorporates the idea that when the interest rate is above its long run average it is pulled down and pulled upward when it is below the long run average. This is a common realistic assumption for the behaviour of interest rates and it is expected that interest rate spreads may also be pulled towards long run equilibrium. We will test in the empirical analysis both the drift element and mean reversion of interest rate spreads by the Vasicek model in the different international markets. Though we concentrate on the single factor case in this study other single factor models could also be used, for example, Cox, Ingersoll and Ross (1985) and Brennan and Schwartz (1980). Indeed multifactor models like the Generalized Vasicek model in Babbs and Nowman (1999) could also be used.

The models are presented below:

$$
\begin{array}{cc}
d r(t)=\alpha d t+\sigma \zeta(d t) & (t \geq 0) \\
d r(t)=\{\alpha+\beta r(t)\} d t+\sigma \zeta(d t) & (t \geq 0)
\end{array}
$$

where $\{r(t), t>0\}$ is the dependent variable the spread, $\alpha$ and $\beta$ are the unknown drift and mean reversion parameters; $\sigma$ is the volatility; $\zeta(d t)$ is a white noise error term precisely defined by Assumption below:

Assumption: $\zeta$ is a random measure defined on all subsets of the half line $0<t<\infty$ with finite Lebesgue measure such that: $E[\zeta(d t)]=0 \quad$ and $\quad E\left[\zeta(d t)^{2}\right]=d t \quad$ and 
$E\left[\zeta\left(\Delta_{1}\right) \zeta\left(\Delta_{2}\right)\right]=0$ for any disjoint sets $\Delta_{1}$ and $\Delta_{2}$ on the half line $0<t<\infty$. See Bergstrom (1984) for a discussion of random measures in econometrics.

To estimate the parameters using the discrete data we use the discrete model derived in Nowman (1997) for the estimation of continuous time models.

$$
\begin{aligned}
& r(t)=e^{\beta} r(t-1)+\frac{\alpha}{\beta}\left(e^{\beta}-1\right)+\eta_{t} \quad(t=1,2, \ldots, T), \\
& E\left(\eta_{s} \eta_{t}\right)=0 \quad(s \neq t) \\
& E\left(\eta_{t}^{2}\right)=\frac{\sigma^{2}}{2 \beta}\left(e^{2 \beta}-1\right)=m_{t t}^{2}
\end{aligned}
$$

The Gaussian estimates are then obtained from the Gaussian likelihood function where $\theta=\left[\alpha, \beta, \sigma^{2}\right]$ and $L(\theta)$ is defined below (see Nowman (1997, Eq.7))

$$
L(\theta)=\sum_{t=1}^{T}\left[2 \log m_{t t}+\frac{\left\{r(t)-e^{\beta} r(t-1)-\frac{\alpha}{\beta}\left(e^{\beta}-1\right)\right\}^{2}}{m_{t t}^{2}}\right]
$$

where we can write

$$
L(\theta)=\sum_{t=1}^{T}\left[2 \log m_{t t}+\varepsilon_{t}^{2}\right]
$$

The transformed residuals $\varepsilon_{1}, \ldots, \varepsilon_{T}$ can be computed from $m_{t t} \varepsilon_{t}=\eta_{t}$.

An alternate dimension is added through the estimation of discrete time models, namely the Autoregressive Moving Average (ARMA), Autoregressive Integrated Moving Average (ARIMA) and Autoregressive Fractionally Integrated Moving Average (ARFIMA) models. These models differ in terms of their underlying assumptions regarding the degree of stationarity of the underlying data series, where the ARMA models assumes that the underlying data series are stationary, the ARIMA model that these are non-stationary, and the ARFIMA models that the data are fractionally integrated. 
We begin with the $\operatorname{ARMA}(p ; . q)$, where this model will have $p$ autoregressive, or lagged variable, and $q$ moving average, or lagged error, terms, thus implying that both previous observations as well as previous disturbance terms have an influence on the current prevailing observation. The ARMA model is therefore specified as follows:

$$
\phi(L)=\mu+\varepsilon_{t}-\theta(L) \varepsilon_{t}
$$

where $\phi(L)$ and $\theta(L)$ denote the polynomials in the lag operator; hence $\phi(L)=1-\phi_{1} L-\phi_{2} L^{2}-\ldots \phi_{p} L^{p}$, where $p$ denotes the number of autoregressive terms in the model, and $\theta(L)=1-\theta_{1} L-\theta_{2} L^{2}-\ldots \theta_{q} L^{q}$, where $q$ denotes the number of moving average terms in the model. As stated above, one of the underlying assumptions for the ARMA models is that the underlying data series follows a stationary, i.e. $I(0)$, process; therefore, should one apply the ARMA model to a non-stationary data series, the results would be spurious. The reason for this is that, should one try to model a non-stationary data series using this one, when the dependent and independent variables are related over time, then one could find that the model has a high measure of fit, even if the two variables are completely unrelated.

The discrete time analysis continues with the $\operatorname{ARIMA}(p ; . d ; . q)$ model, developed by Box and Jenkins (1976), which provides a contrast to the ARMA model by assuming that the underlying data series follows a non-stationary process. Once again this has $p$ autoregressive and q moving average terms, as was the case of the ARMA model; however, this model extends the ARMA model in that it also has a $d$ component, where this measures the number of times that the underlying data series has to be differenced in order to make the process stationary, where $d \geq 1$ and an integer. The ARIMA model is therefore specified as:

$$
\phi(L)\left[(1-L)^{d} y_{t}\right]=\mu+\theta(L) \varepsilon_{t}
$$


where $\phi(L)$ and $\theta(L)$ denote the polynomials in the lag operator, as described in the note to Expression (7) above; $p$ and $q$ denote the number of autoregressive and moving average terms, respectively; and $(1-L)^{d}=\Delta^{d} y_{t}$ is the $d$ th difference of $y_{t}$.

The final alternative model is the $\operatorname{ARFIMA}(p ; . d ; . q)$, first introduced by Granger and Joyuex (1980), Granger (1980, 1981) and Hosking (1981), where the assumption is made that the underlying data series follow a mean reverting process, however, the Wold decomposition and the autocorrelation coefficients for this process will exhibit a very slow hyperbolic rate of decay, where, the higher the value of $d$, the slower the rate of decay. As was the case for the ARMA and ARIMA models, this model has $p$ autoregressive and q moving average terms. Furthermore, like the ARIMA model, it also has a $d$ component, where this measures the number of times that the underlying data series has to be differenced in order to make the process stationary, however, in this case $0<d<1$. The ARFIMA model parameterises the conditional mean of the series generating process as an $\operatorname{ARFIMA}(p ; . d ; . q)$ process, which is specified as follows:

$$
\phi(L)(1-L)^{d}\left(y_{t}-\mu\right)=\theta(L) \varepsilon_{t}
$$

where $\phi(L)$ and $\theta(L)$ denote the polynomials in the lag operator, as described in the note to Expression (9) above, where all the roots of $\phi(L)$ and $\theta(L)$ lie outside the unit root circle; $p$ and $q$ denote the number of autoregressive and moving average terms, respectively; $d$ denotes the fractional differencing parameter; and $\varepsilon_{t}$ is white noise. This model is estimated using the Maximum Likelihood Estimation (MLE) method outlined in Sowell (1986, 1992), where the proposed log-likelihood function is then:

$$
\ell=-\frac{T}{2} \log (2 \pi)-\frac{1}{2} \log |\Omega|-\frac{1}{2} Y^{\prime} \Omega^{-1} Y
$$


where $\{\Omega\}_{i: . j}=\gamma_{|i-j|}$, where $\gamma$ denotes the autocovariances of the ARFIMA process, and $Y$ represents a $T$-dimensional vector of the observation on the process $y_{t}$. One should note that the Wold decomposition and the autocorrelation coefficients for this process will exhibit a very slow rate of decay, where the higher the value of $d$, the slower the decay. Furthermore, in the case of the first-difference, of the series, where $-0.5<d<0.5$, the process is covariance stationary, while, should $(0.5<d<1)$, the process would be fractionally integrated. This being said, as long as $d<1$, the process will exhibit mean-reversion.

\section{Data}

The data sets used in this study for the UK comprise the monthly 15, 20 and 25-year Treasury yield spreads, relative to the 1-month yield obtained from the Bank of England ${ }^{2}$. The monthly data covers the period January 1998 to December 2010. For Germany, Japan and the US weekly data on the 10-year Treasury spreads relative to the 1-month interbank offered rate over the period January 2000 to December 2010 are used $^{3}$. The interbank short rate is published by the British Bankers Association (BBA) obtained from Datastream and is used as a proxy at the short end of the curve. The other bond yields were obtained from Datastream. Figures 1 to 3 provide graphs of the spreads and the change in the spreads for each data set respectively.

\section{[Insert Figures 1-3 about here]}

\section{[Insert Tables 1-3 about here]}

Table1 and Table 2 provide summary statistics of both the levels and first-differences of the spreads, respectively. The average spread for the UK data varies from $0.233 \%$ to $0.397 \%$, with standard deviations ranging from $1.647 \%$ to $1.818 \%$. An interesting observation is that

\footnotetext{
${ }^{2}$ We use monthly data for the UK as the data is only available daily and monthly.

${ }^{3}$ Many different types of spreads can be used. Smith (2012) looks at the spread between LIBOR and OIS rates, the LOIS spread. One could also use both uncollateralized and collateralized rates (repos) or even swap rates (e.g. EONIA). One could also model different interest rate spreads like only the very short rate (1 week) interest rate spreads.
} 
the average value of the spread decreases while the standard deviation of the spread increases with the maturity of the spread, hence the 15 -year spread is observed to have a higher average and lower standard deviation than the 25 -year spread. For Germany the average spread is $1.202 \%$ with standard deviation of $0.926 \%$, for Japan the average spread is $1.178 \%$ with standard deviation of $0.315 \%$ and for the US the average spread is $1.448 \%$ with standard deviation of $1.505 \%$. For UK spreads it was found they exhibit significant autocorrelation across all maturities and lags. Furthermore, the US spread were found to exhibit significant autocorrelation up to the sixth lag, with mixed results for the Japanese spread and the German spread exhibiting no significant autocorrelation, with the possible exception of the first lag.

Having outlined the characteristics of the data, standard unit roots tests were performed on the respective spreads in order to determine the order of integration and thereby provide a preliminary indication of the most appropriate discrete time model, where the results of these tests are presented in Table 3. The results from the Augmented Dickey-Fuller (Dickey and Fuller (1981)) and Phillips-Perron (Phillips and Perron (1988)) unit root tests are unanimous in indicating that the levels of spreads are non-stationary, with the possible exception of the Japanese spread, where these are found to be significantly stationary at a 5\% level of significance. When examining the results from the KPSS unit root tests (see Kwiatkowski, et al. (1992)), the results are somewhat more mixed. These results indicate that when examining UK spreads, these were found to only be non-stationary at the 5\% and $10 \%$ levels of significance. Examining the results for the international spreads, both the German and Japanese spreads are found to be stationary, while the Japanese spread is only non-stationary at the $5 \%$ and $10 \%$ levels of significance. ${ }^{4}$ The fact that the results of these unit root tests are mixed gives a preliminary indication that interest rates spreads may follow a fractionally

\footnotetext{
${ }^{4}$ One should note that the first-difference of all interest rate spreads is found to be stationary.
} 
integrated process in that this lies somewhere in between the arguments of stationarity and non-stationarity.

\section{Empirical results}

The empirical results for the continuous time models of Merton (1973) and Vasicek (1977) are presented in Table $4^{5}$. For the UK data the Merton model drift is significant across the curve, while the Vasicek model does not display any evidence of mean revision. Turning to Germany for the Vasciek model the drift and mean revision are significant. For Japan in the Merton and Vasciek model the drift is significant but no evidence of mean revision in the Vasicek model. Lastly for the US in the Vasicek model the drift and mean revision are significant.

Having outlined the results from the continuous time estimation, we now move on to examine those from the discrete time models. Given the mixed unit root test results for these data series, as discussed in Section 3, $\operatorname{ARMA}(0 ; ; 0)$ through $\operatorname{ARMA}(3 . ; 3)$ models were estimated using UK and international spreads data, where the best specification for each data series is selected on the basis of the log-likelihood value, Akaike Information Criterion (AIC) (see Akaike (1974)) and the Schwartz-Bayesian Information Criterion (SBIC) (see Schwartz (1978)). The results from these best specifications are presented in Table 5, where the best model is found to be an ARMA(1.;0) across all data series. Therefore one can conclude that UK and international interest rate spreads from the previous period will have a significant impact on current spreads.

\section{[Insert Table 5 about here]}

Given the fact that the unit root tests presented in Section 3 provided mixed evidence of non-stationarity for the UK monthly and international spreads, $\operatorname{ARIMA}(0 . ; 1 . ; 0)$ through

\footnotetext{
${ }^{5}$ All estimates reported in the tables are based on annualized interest rate data.
} 
$\operatorname{ARIMA}(3 . ; 1 . ; 3)$ models were estimated across all data series, where once again the best model is selected on the basis of the log-likelihood, AIC and SBIC measures. The results from these models are presented in Table 6 . The best models for the UK spreads, presented in Panel A, are found to be either an $\operatorname{ARIMA}(1 . ; 1 . ; 0)$ for the 20-year spread, or an ARIMA(1.;1.;1), for the 15 and 25-year spreads. When looking at the international spreads, presented in Panel B, the best specification for the German 10-year spread was found to be an $\operatorname{ARIMA}(0 . ; 1 . ; 1)$ and for the US 10-year spread an $\operatorname{ARIMA}(1 . ; 1 . ; 0)$. None of the specifications for the Japanese 10-year spread are found to be significant at any conventional level of significance. One can therefore conclude, that with the exception of the German and Japanese spreads, there appears to be a significant autoregressive component in the firstdifference of interest rate spreads, hence changes in the spreads during the previous period are found to have a significant impact on the current changes in the spreads. Furthermore, with the exception of the UK monthly 20-year spread and the Japanese and US spreads, the significant moving average coefficient for the first-difference indicates that shocks experienced during the previous period are found to have a significant impact on the current change in the interest rate spreads.

\section{[Insert Table 6 about here]}

As stated previously, the underlying assumption of the ARMA and ARIMA models is that the underlying data series follows either a stationary or non-stationary process, respectively. An interesting approach would be to extend this by arguing the interest rate spreads are fractionally integrated, hence shocks to interest rate spreads will not decay exponentially, as would be the case under the assumption of stationarity, nor would they persist indefinitely, as would be the case under the assumption of non-stationarity, instead, they would decay hyperbolically thereby indicating a delay in the mean reversion process. In 
order to investigate this alternate hypothesis, $\operatorname{ARFIMA}(0 . ; d ; 0)$ through $\operatorname{ARFIMA}(3 . ; d ; ; 3)$ models are estimated across all data series, where, as was the case previously, the best model is selected on the basis of the log-likelihood, AIC and SBIC measures. The results from these best specifications are presented in Table 7.

\section{[Insert Table 7 about here]}

The results indicate that the value for the $d$-parameter is found to range between 0.620 and 1.007, hence, with the possible exception of Japanese spreads, which appear to exhibit non-stationary behaviour, all interest rate spreads are found to be fractionally integrated and mean reverting. The result for the Japanese spreads is not surprising in Japanese interests rates have remained suppressed since the collapse of Japanese banks in the early 1990s. Moving onto examine the lag structure, the results for the UK spreads are uniform in that prevailing interest rate spreads during the previous two periods are found to have a significant impact on current spreads, while past shocks are found to have no impact at all.

Examining the lag structure results for the international spreads, German 10-year spreads during the previous two periods are found to have a significant impact, while for the US 10-year spread, it is only the previous period that has a significant impact. In both cases past shocks are found to have no significant impact on interest rate spreads. In contradistinction, Japanese 10-year spreads are not only found to exhibit non-stationary behaviour, as discussed above, but these results indicate that while only the previous period has a significant impact on current prevailing spreads, as was the case for the US 10-year spread, however, unlike the other spreads, with exception of the UK 15-year daily spread, shocks over the past three periods are found to have a significant impact on the current prevailing spread.

\section{Forecast Performance}

Having outlined the in-sample characteristics of the interest spreads, above, we now compare the different methodologies based on their ex-post dynamic forecasts over out-of- 
sample periods. Forecasts were performed for each of the models for the UK data over the period January 2011 and April 2011, while for Germany, Japan and the US over the period January 2011 and July 2011. Figures 4 to 6 provide a graphical comparison of the forecasts for each respective model with the actual value at that corresponding period. One interesting observation in the international markets is the forecasting performance of the Vasicek model is less satisfactory compared to the Merton model.

\section{[Insert Figures 4-6 about here]}

The forecasts from all models were then compared using the mean and variance of the forecast errors, to test for bias, and using the Mean Absolute Percentage Error (MAPE), Root Mean Squared Error (RMSE) and Percentage Correct Direction Predicted (CDIR) forecast metrics, where the last three metrics are calculated as follows:

$$
\begin{aligned}
& M A P E=100 \times\left\{\frac{1}{M} \sum_{i=1}^{M}\left|\left(\frac{r_{i}^{a}-r_{i}^{f}}{r_{i}^{a}}\right)\right|\right\} \\
& R M S E=\sqrt{\frac{1}{M} \sum_{i=1}^{M}\left(r_{i}^{a}-r_{i}^{f}\right)^{2}} \\
& C D I R=\frac{1}{M} \sum_{i=1}^{M} z_{i}
\end{aligned}
$$

where $r_{i}^{a}$ denotes the actual observed value at time $i, r_{i}^{f}$ denotes the forecasted value at time $i, M$ denotes the forecast horizon, and $z_{i}=1$ if $\left(r_{i}^{a}-r_{i-1}^{a}\right)$ and $\left(r_{i}^{f}-r_{i-1}^{a}\right)>0$ and $z_{i}=0$.

The rationale behind the selection of these three forecast metrics is that while the RMSE provides a quadratic loss function, which would be useful if we were to consider large forecast errors as egregious, this would be viewed as a disadvantage if this was not the case. Dielman (1986) proposes that, in cases where there are outliers, the MAPE should be used, with Makridakis (1993) argue that the MAPE incorporates the best characteristics among the 
various measures of forecast accuracy. This being said, in practical terms, the fact that forecast errors are minimised might not actually provide any guidance as to the potential profitability of employing the respective model in a market trading strategy (see Gerlow, et al. (1993) for a more detailed discussion on this matter). For this reason, Refenes (1995) proposed the use of the CDIR as indication of the best model.

[Insert Table 8 about here]

Table 8 presents the forecast metrics for each model and data set, respectively, with some interesting findings. The continuous time Merton model outperforms all other model specifications in terms of the mean of the forecast errors, MAPE and RMSE. In economic terms the RMSE are very small for the Merton model being less than one percent across the international markets. This compares favourably to other studies on forecasting rates (see for example, Nowman (2001), Nowman and Saltoglu (2003), Bergstrom and Nowman (2007)). Examining the variance of the forecast errors, the ARMA model was found to have the lowest variance for all UK spreads and the ARFIMA model for German spreads. For Japanese and US spreads the Merton model performed well. The final forecast metric, i.e. the CDIR, provided somewhat mixed results in that only in the case of the German and US spreads could we determine a clear winner, i.e. the ARMA model. Interestingly, the Vasicek model did not perform as well as expected, although this may be a result of there being insufficient data for the mean reversion characteristics of the interest spreads to be determined. Overall the continuous time Merton model forecast results estimated by the Gaussian estimation methods supports other empirical continuous time models using these methods, for example, Chambers (1993), Bergstrom, Nowman and Wymer (1992) and Bergstrom and Nowman (2007).

\section{Conclusions}


The study aimed at modelling and forecasting the interest rate spread using continuous time and discrete time modelling approaches. Two well known interest rate models were employed and tested against discrete time ARMA and ARFIMA models. The study looked at four major financial markets the UK, US, Japan and Germany. Using monthly and weekly data which covers the important recent global financial market crisis of 2007-2009 which affected all these markets we provided empirical evidence of the models fit historically. Extensive forecasting performance of the models was carried out. We find that the continuous time modelling methodology in terms of the Merton model using the Gaussian estimation method outperforms all other model specifications in terms of the mean of the forecast errors, MAPE and RMSE. Further research on other international spreads would be useful in the future with different methodologies. 


\section{References}

Akaike, H. (1974) 'A new look at the statistical model identification', IEEE Transactions on Automatic Control, Vol.19, pp.716-723.

Ang, A., Piazzesi, M. and Wei, M. (2006) 'What does the yield curve tell us about gdp growth?', Journal of Econometrics, Vol.131, pp.359-403.

Aretz, K. and Peel, D. A. (2008) 'Spreads versus professional forecasters as predictors of future output change', Working Paper, Lancaster University.

Babbs, S. H., and Nowman, K. B. (1999) 'Kalman filtering of generalized vasicek term structure models', Journal of Financial and Quantitative Analysis, Vol.34, pp.115-130.

Backus, D. K. and Zin, S. E. (1993) 'Long-Memory Inflation Uncertainty: Evidence from the Term Structure of Interest Rates', Journal of Money, Credit and Banking, 25, pp.681-708.

Bergstrom, A. R. (1983) 'Gaussian estimation of structural parameters in higher-order continuous time dynamic models', Econometrica, Vol.51, pp.117-152.

Bergstrom A.R. (1984) 'Continuous time stochastic models and issues of aggregation over time', In: Griliches, Z., Intriligator, M.D. (Eds.), Handbook of Econometrics, Vol. II. Elsevier Science: Amsterdam.

Bergstrom, A. R. (1990) Continuous Time Econometric Modelling, Oxford: Oxford University Press.

Bergstrom, A. R., Nowman, K. B. and Wymer, C. R. (1992) 'Gaussian estimation of a second order continuous time macroeconometric model of the United Kingdom', Economic Modelling 9, pp.313-351.

Bergstrom, A. R. and Nowman, K. B. (2007) A Continuous Time Econometric Model of the United Kingdom with Stochastic Trends, Cambridge: Cambridge University Press.

Bernard, H. and Gerlach, S. (1998) 'Does the term structure predict recessions? the international evidence', International Journal of Finance and Economics, Vol.3, pp.195-215. 
Bordo, M. D. and Haubrich, J. G. (2008) 'The yield curve as a predictor of growth: long-run evidence, 1875-1997', Review of Economics and Statistics, Vol.90, pp.182-185.

Box, G. E. P. and Jenkins, G. M. (1976) Time Series Analysis: Forecasting and Control, San Francisco, Holden-Day.

Brennan, M. J., and Schwartz, E. S. (1980) 'Analyzing convertible securities', Journal of Financial and Quantitative Analysis, Vol.15, pp.907-929.

Campbell, J. Y. and Schiller, R. Y. (1987) 'Cointegration and tests of present value models', Journal of Political Economy, 95 pp. 1062-1088.

Chambers, M. J. (1993) 'Forecasting with continuous-time and discrete-time models: an empirical comparison', in Phillips, P. C. B. (ed.) Models, Method, and Applications of Econometrics, Blackwell, Oxford.

Cox, J. C., Ingersoll, J. E., Ross, S. A. (1985) 'A theory of the term structure of interest rates', Econometrica 53, pp. 385-407.

Crato, N. and Rothman, P. (1994) Fractional integration analysis of long-run behaviour for US macroeconomic time series, Economics Letters, 45, pp.287-291.

Debt Management Office (2012). UK government securities: a guide to gilts, $10^{\text {th }}$ Edition, Debt Management Office, UK.

Dickey, D.A. and Fuller, W. A. (1981) 'Likelihood ratio statistics for autoregressive time series with a unit root', Econometrica, Vol.49, pp.1057-1072.

Dielman, T. E. (1986) A comparison of forecasts from least absolute value and least squares regression, Journal of Forecasting, 5, pp.189-195.

Duarte, A., Venetis, I. A. and Paya, I. (2005) 'Predicting real growth and the probability of recession in the euro area using the yield spread', International Journal of Forecasting, Vol.21,:pp.262-277. 
Estrella, A. and Mishkin, F. S. (1998) 'Predicting U.S. recessions: financial variables as leading indicators', Review of Economic and Statistics, Vol.80, pp.45-61.

Estrella, A. and Hardouvelis, G. A. (1991) 'The term structure as a predictor of real economic activity', Journal of Finance, Vol.46, pp.555-576.

Estrella, A., Rodrigues, A. P. and Schich, S. (2003) How stable is the predictive power of the yield curve? evidence from Germany and the United States, Review of Economic and Statistics, 85, pp.629-644.

Fama, E. F. (1984) The information in the term structure, Journal of Financial Economics, 13, pp.509-528.

Fama, E. F. (1990), Term structure forecasts of interest rates, inflation and real returns, Journal of Monetary Economics, 25, pp.59-76.

Galvao, A. B. C. (2006) 'Structural break threshold vars for predicting U.S. recessions using the spread', Journal of Applied Econometrics, Vol.21, pp.463-487.

Gerlow, M. E., Irwin, S. H. and Liu, T. R. (1993) Economic evaluation of commodity price forecasting models, International Journal of Forecasting, 9, pp.387-397.

Granger, C. W. J. (1980) 'Long memory relationships and the aggregation of dynamic models', Journal of Econometrics, Vol.14, pp.227-238.

Granger, C. W. J. (1981) 'Some properties of time series data and their use in econometric model specification', Journal of Econometrics, Vol.16, pp.121-130.

Granger, C. W. J. and Joyeux, R. (1980) 'An introduction to long-memory time series models and fractional differencing', Journal of Time Series Analysis, Vol.1, pp.15-29.

Hardouvelis, G. A. (1988) The predictive power of the term structure during recent monetary regimes, Journal of Finance, 43, pp.339-356.

Harvey, C. R. (1988) 'The real term structure and consumption growth', Journal of Financial Economics, Vol.22, pp.305-333. 
Harvey, C. R. (1989) 'Forecasts of economic growth from the bond and stock markets', Financial Analysts Journal, Vol.45, pp.38-45.

Hosking, J. R. M. (1981) 'Fractional differencing', Biometrika, Vol.68, pp.165-176.

Ivanova, D. Lahiri, K. and Seitz. F. (2000) 'Interest rate spreads as predictors of german inflation and business cycles', International Journal of Forecasting, Vol.16, pp.39-58.

Kwiatkowski, D., Phillips, P. C. B., Schmidt P., and Shin, Y. (1992) 'Testing the null hypothesis of a unit root against the alternative of a unit root: how sure are we that economic time series have a unit root', Journal of Econometrics, Vol.54, pp.159-178.

Laurent, R. D. (1988) 'An interest rate-based indicator of monetary policy', Federal Reserve Bank of Chicago Economic Perspectives, Vol.12, pp.3-14.

Makridakis, S. (1993) 'Accuracy measures: theoretical and practical concerns, International Journal of Forecasting, 9, pp.527-529.

Merton, R. C. (1973) 'Theory of rational option pricing', Bell Journal of Economics and Management Science Vol.4, pp.141-183.

Nakaota, H. (2005) 'The term structure of interest rates in Japan: the predictability of economic activity', Japan and the World Economy, Vol.17, pp.311-326.

Nowman, K. B. (1997) 'Gaussian estimation of single-factor continuous time models of the term structure of interest rates', Journal of Finance, Vol.52, pp.1695-1706.

Nowman, K. B. (2001) 'Gaussian estimation and forecasting of multi-factor term structure models with an application to japan and the united kingdom', Asia Pacific Financial Markets, Vol.8, pp.23-34.

Nowman, K. B. (2003) 'A note on gaussian estimation of the CKLS and CIR models with feedback effects for japan', Asia Pacific Financial Markets, Vol.10, pp.275-279.

Nowman, K. B. and Saltoglu, B. (2003) 'Continuous time and nonparametric modelling of U.S. interest rate models', International Review of Financial Analysis, 12, pp.25-34. 
Nowman, K. B. (2006) 'Continuous time interest rate models in japanese fixed income markets', in: J. A., Batten, Fetherston, T. A., \& Szilagyi, P. G. (Eds.), Japanese Fixed Income Markets, Elsevier, pp. 321-346.

Phillips, P. C. B. and Perron, P. (1988) 'Testing for a unit root in time series regression', Biometrika, Vol.75, pp.335-346.

Refenes, A. P. (1995). Neural Networks in the Capital Markets, John Wiley, Chichester, UK. Rosenberg, J. V. and Maurer, S. (2008) 'Signal or noise? implications of the term premium for recession forecasting', Federal Reserve Bank of New York Economic Policy Review, Vol.14, pp.1-11.

Schwartz, G. (1978) 'Estimating the dimension of a model', The Annals of Statistics, Vol.6, pp.461-464.

Shaaf, M. (2000) 'Predicting recessions using the yield curve: an artificial intelligence and econometric comparison', Eastern Economic Journal, Vol.26, pp.171-190.

Shea, G. S. (1991) 'Uncertainty and implied variance bounds in long memory models of the interest rate term structure, Empirical Economics, 16, pp.287-312.

Smith, J. (2012) 'The term structure of money market spreads during the financial crisis', Unpublished paper, Stern School of Business, New York University.

Sowell, F. (1986) 'Fractionally integrated vector time series', Working Paper, Department of Economics, Duke University, Durham, NC.

Sowell, F. (1992) 'Maximum likelihood estimation of stationary univariate fractionally integrated time series model', Journal of Econometrics, Vol.53, pp.165-188.

Treasury Bulletin (2013) 'Treasury bulletin', June 2013, Department of the Treasury.

Vasicek, O. (1977) 'An equilibrium characterization of the term structure', Journal of Financial Economics, Vol.5, pp.177-188. 
Venetis, I. A., Paya, I. and Peel, D. A. (2003) 'Re-examination of the predictability of economic activity using the yield spread: a nonlinear approach', International Review of Economics and Finance, Vol.12, pp.187-207.

Wheelock, D. C. and Wohar, M. E. (2009) 'Can the term spread predict output growth and recessions? a survey of the literature', Federal Reserve Bank of St. Louis Review, Sept/Oct, Part 1, pp.419-440.

Yoshino, N. (2008). Bond market development in Japan. Unpublished paper, Keio University. 
Figure 1: UK Interest Rate Spreads
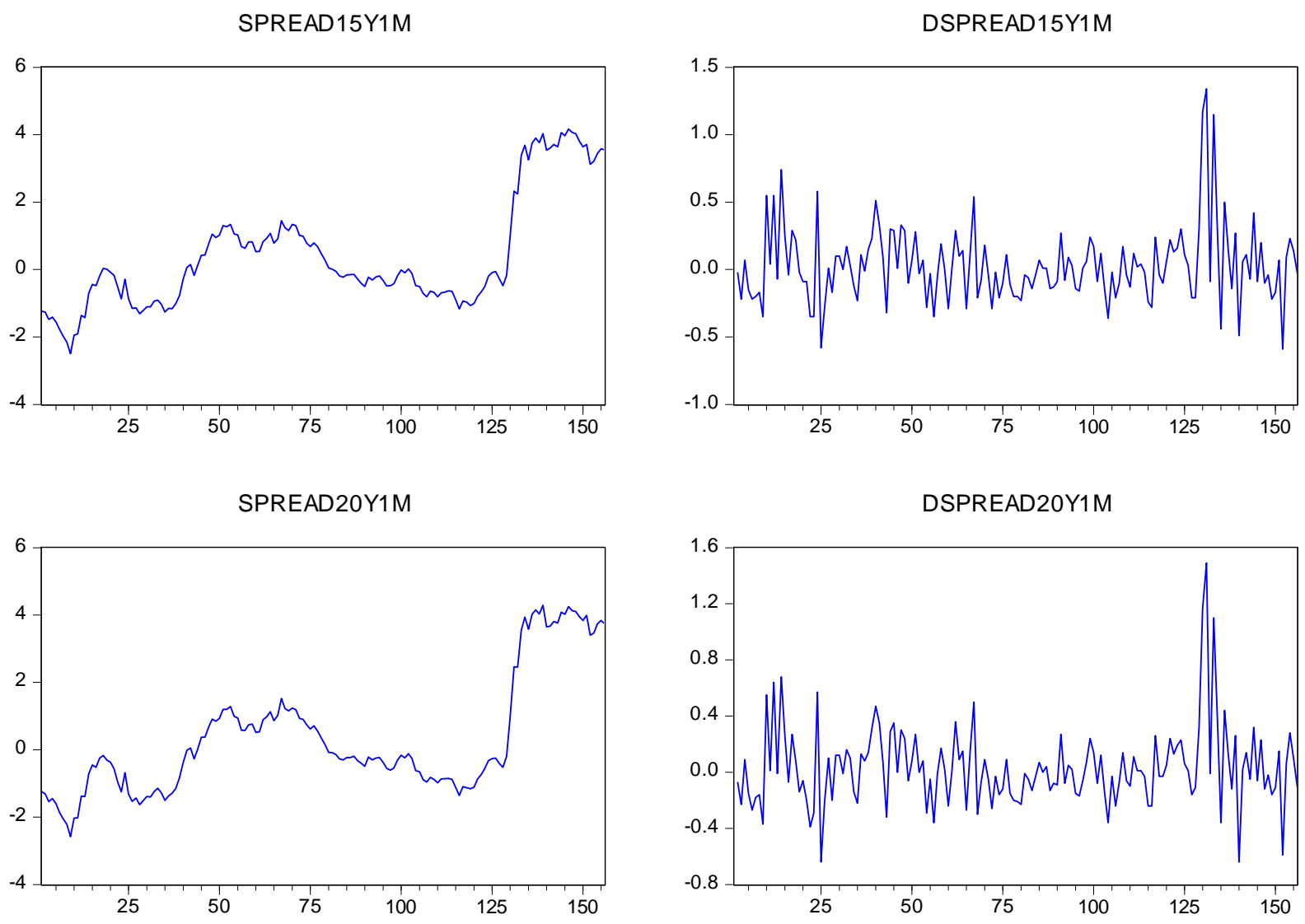

SPREAD25Y1M

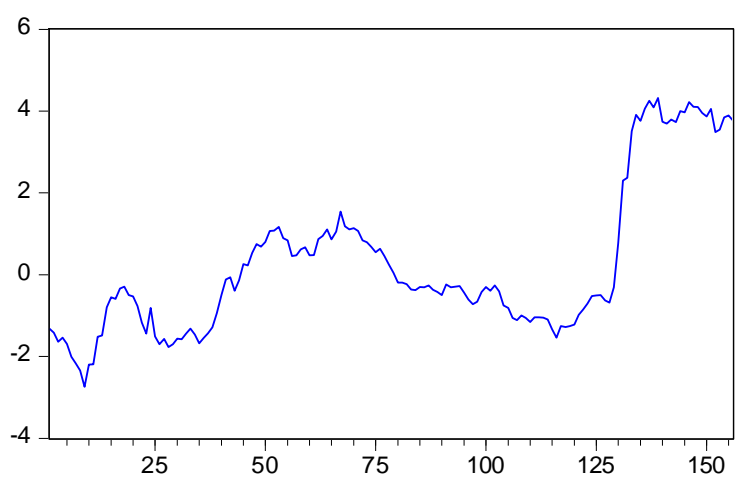

DSPREAD25Y1M

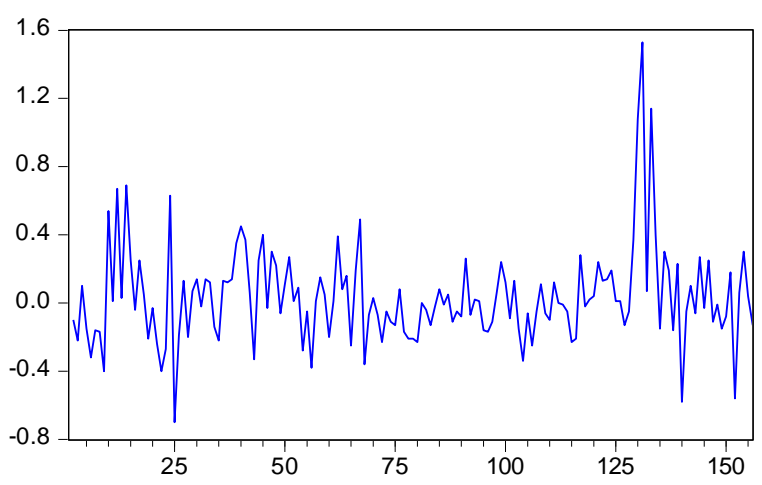

Figure 1: Monthly UK Spreads 
Figure 2: US and German Interest Rate Spreads

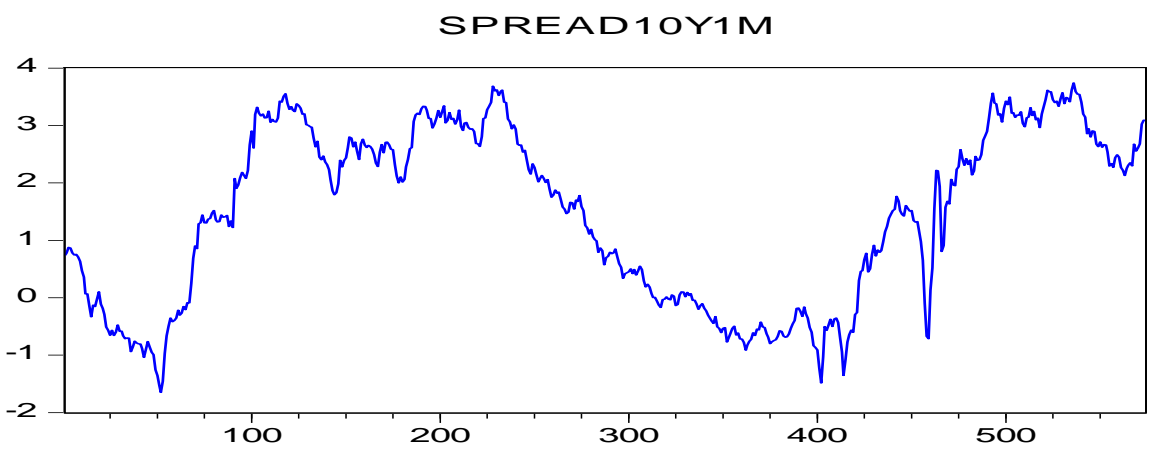

DSPREAD1OY1M
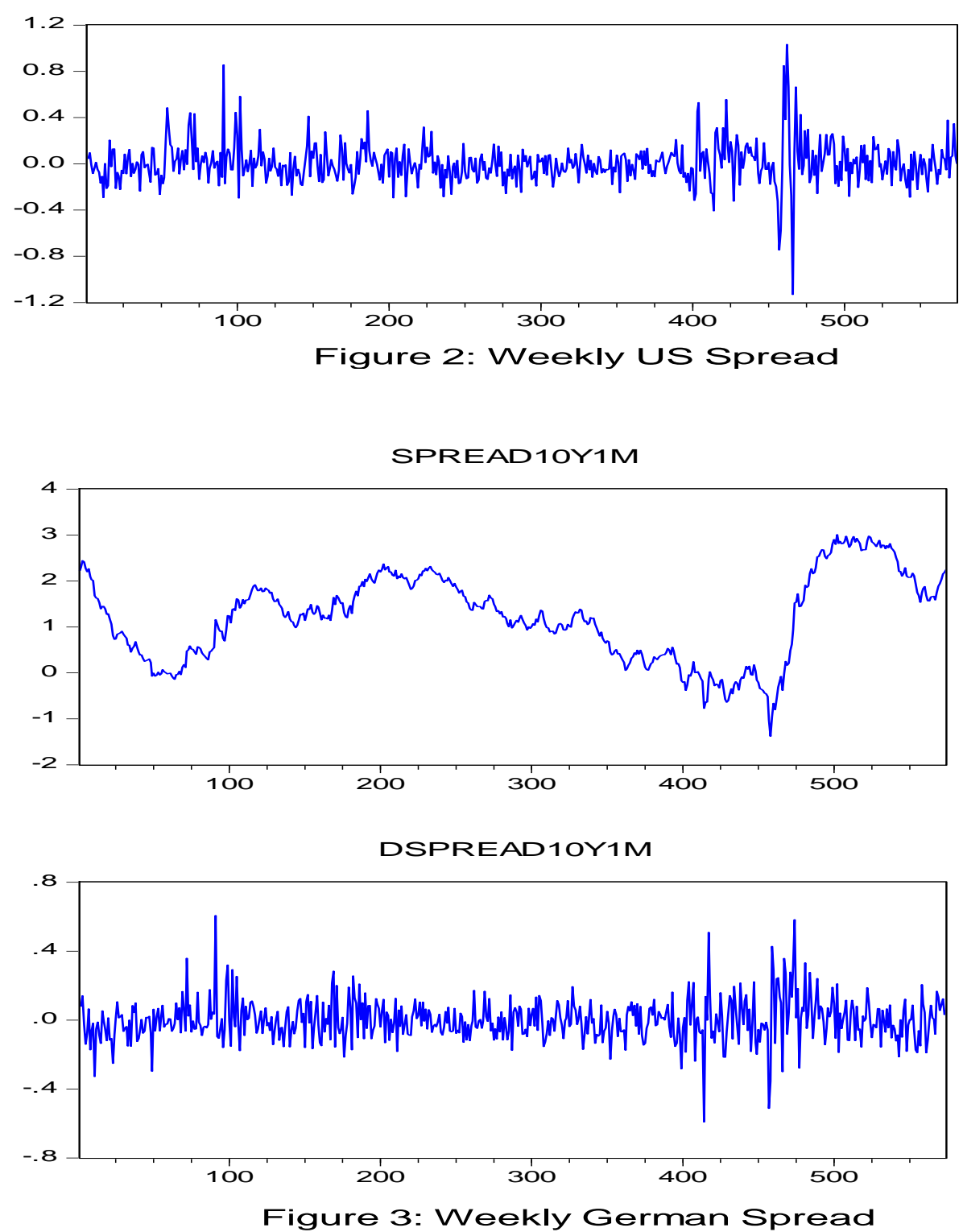
Figure 3: Japan Interest Rate Spread
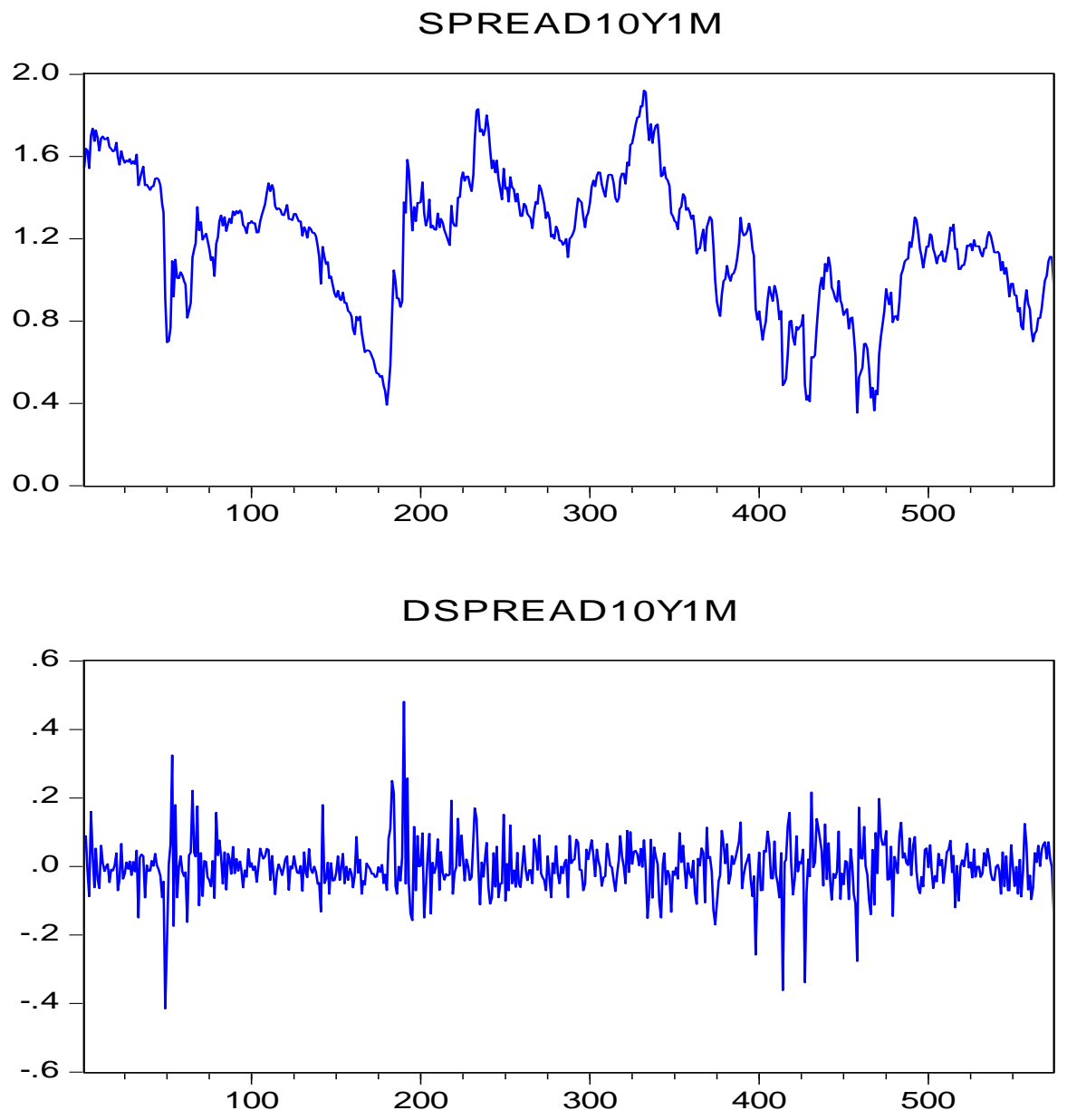

Figure 4: Weekly Japan Spread 
Figure 4: Actual vs. Forecasted UK 15-Year and UK 20-Year Spreads

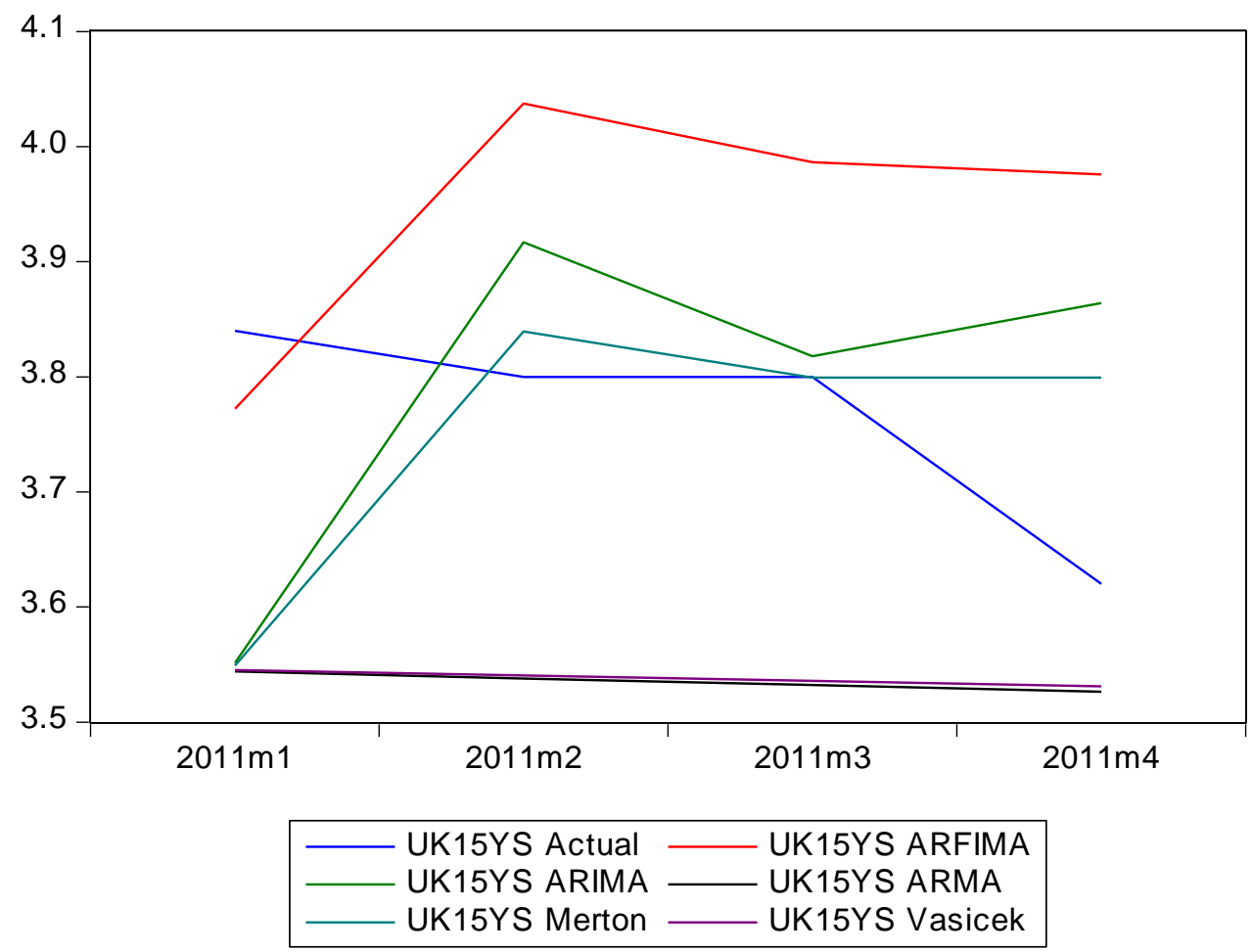

UK 15-Year Treasury Yield Spreads

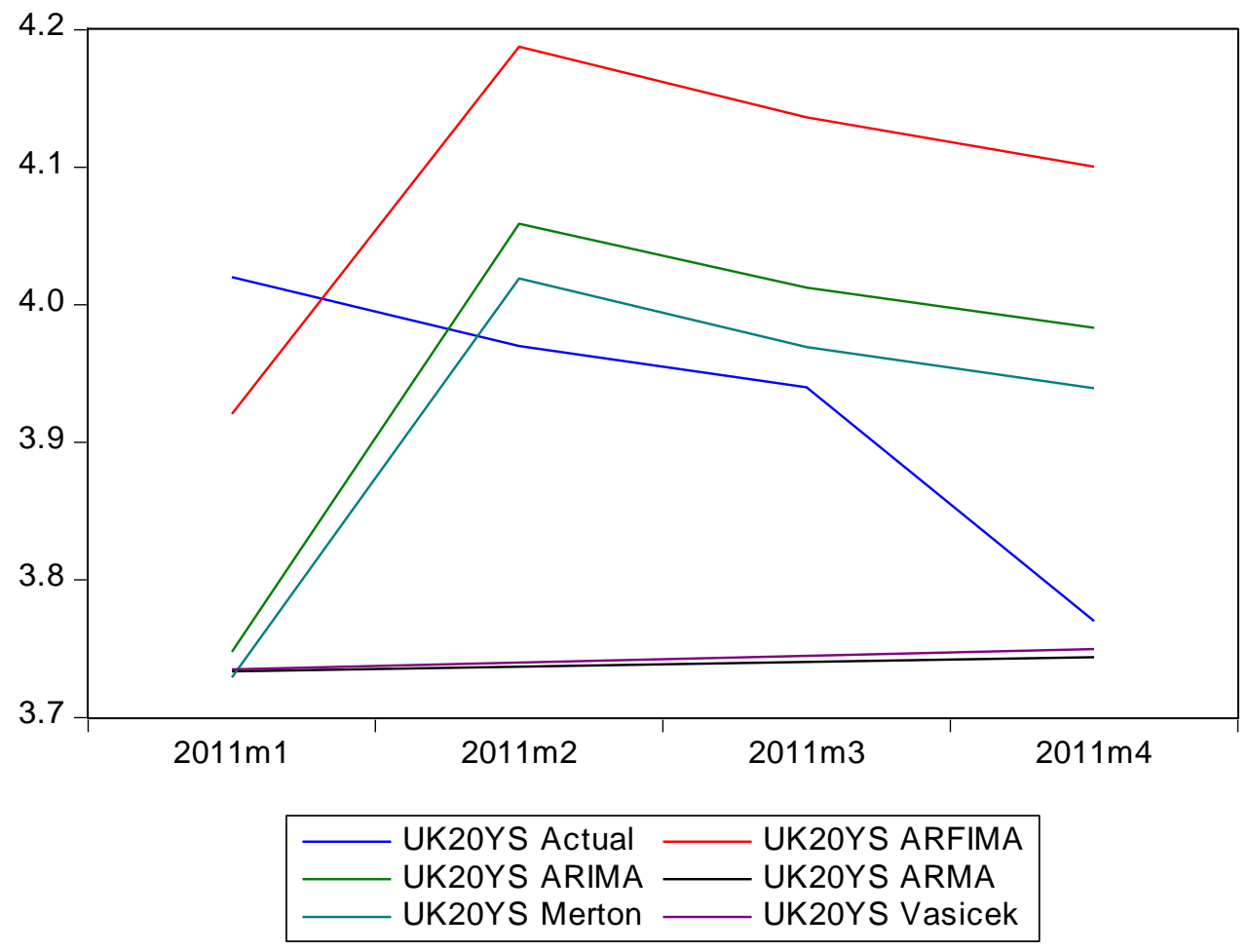

UK 20-Year Treasury Yield Spreads 
Figure 5: Actual vs. Forecasted UK 25-Year and German 10-Year Spreads

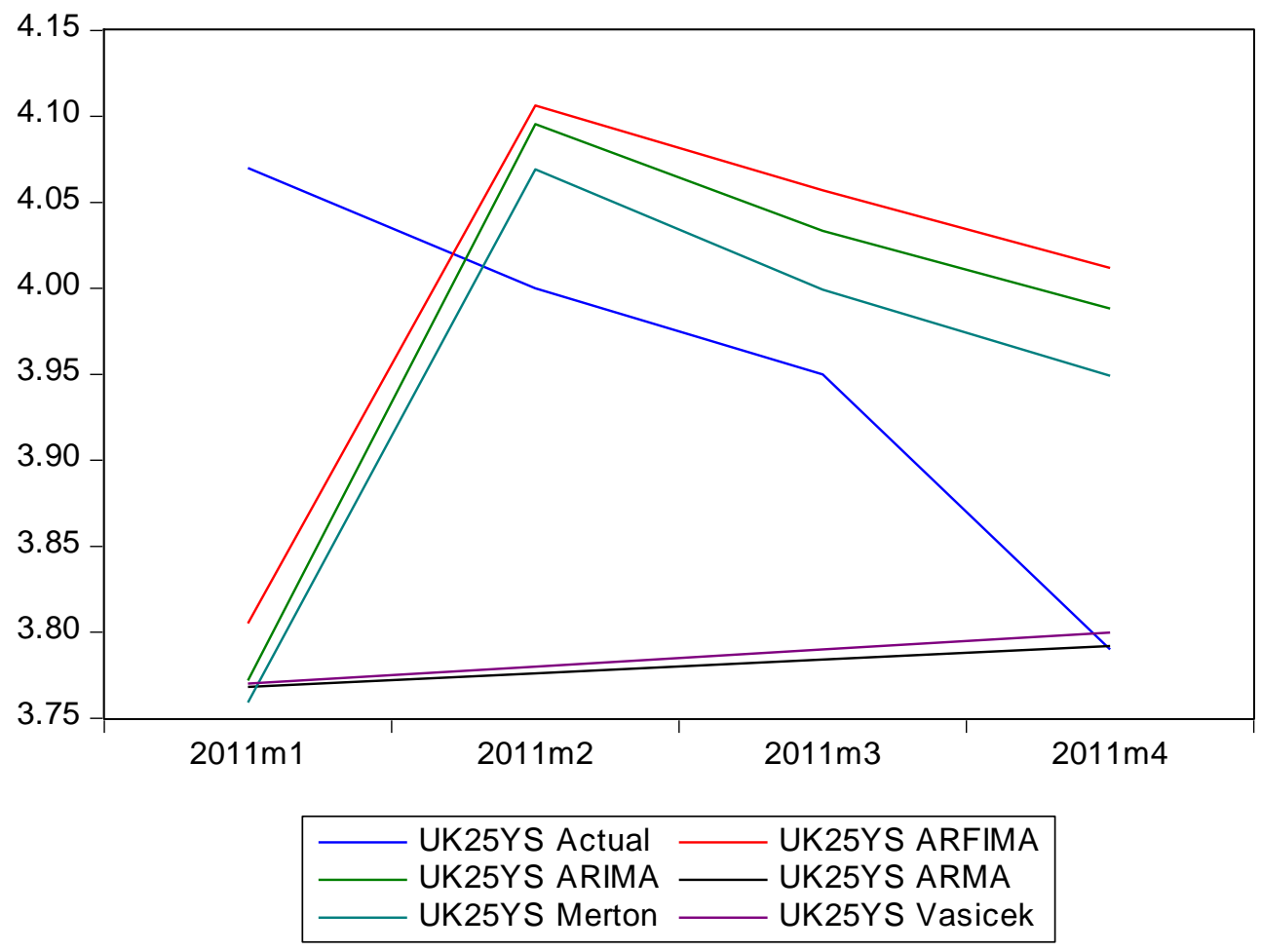

UK 25-Year Treasury Yield Spreads

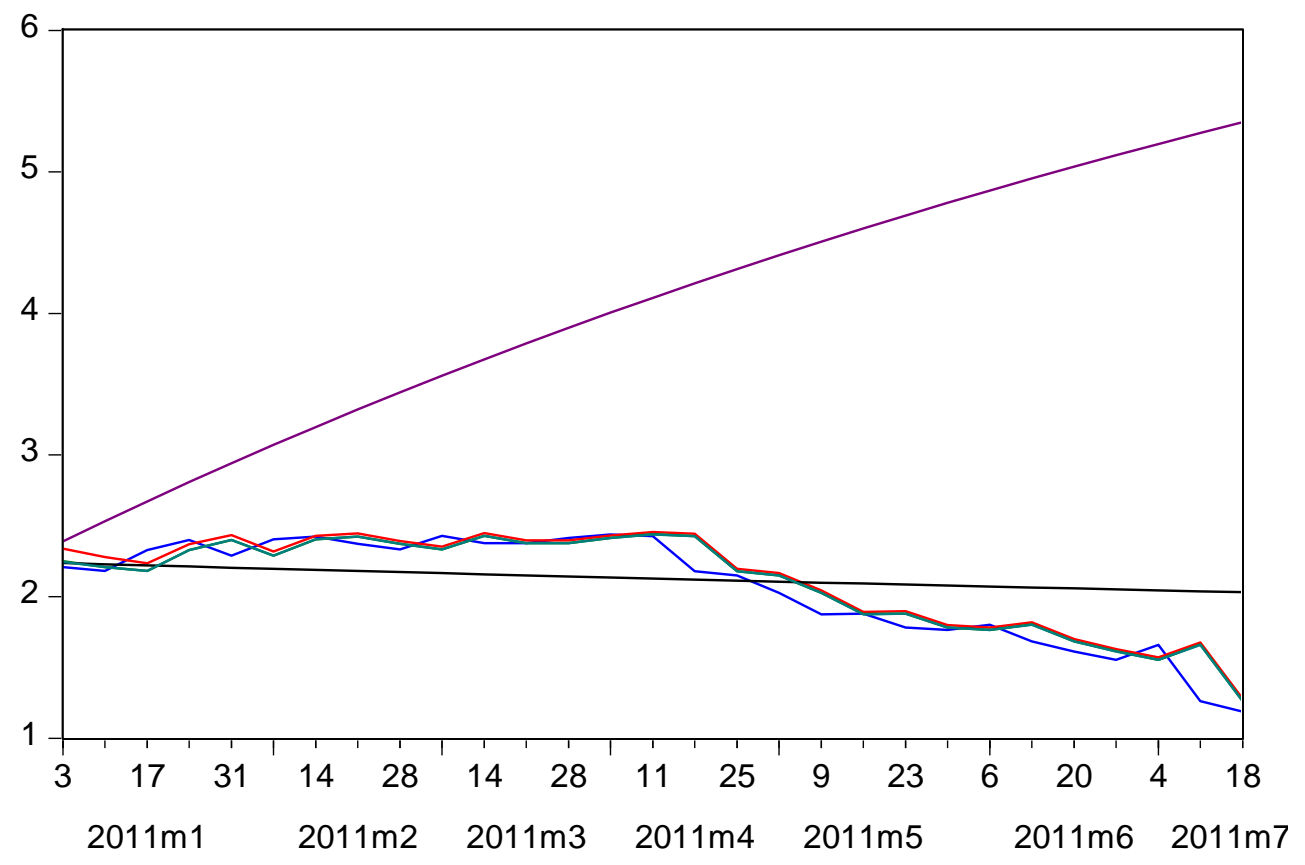

\begin{tabular}{rr|}
\hline GER10YS Actual & GER10YS ARFIMA \\
GER10YS ARIMA & GER10YS ARMA \\
GER10YS Merton & GER10YS Vasicek \\
\hline
\end{tabular}

German 10-Year Treasury Yield Spreads 
Figure 6: Actual vs. Forecasted Japanese and US 10-Year Spreads

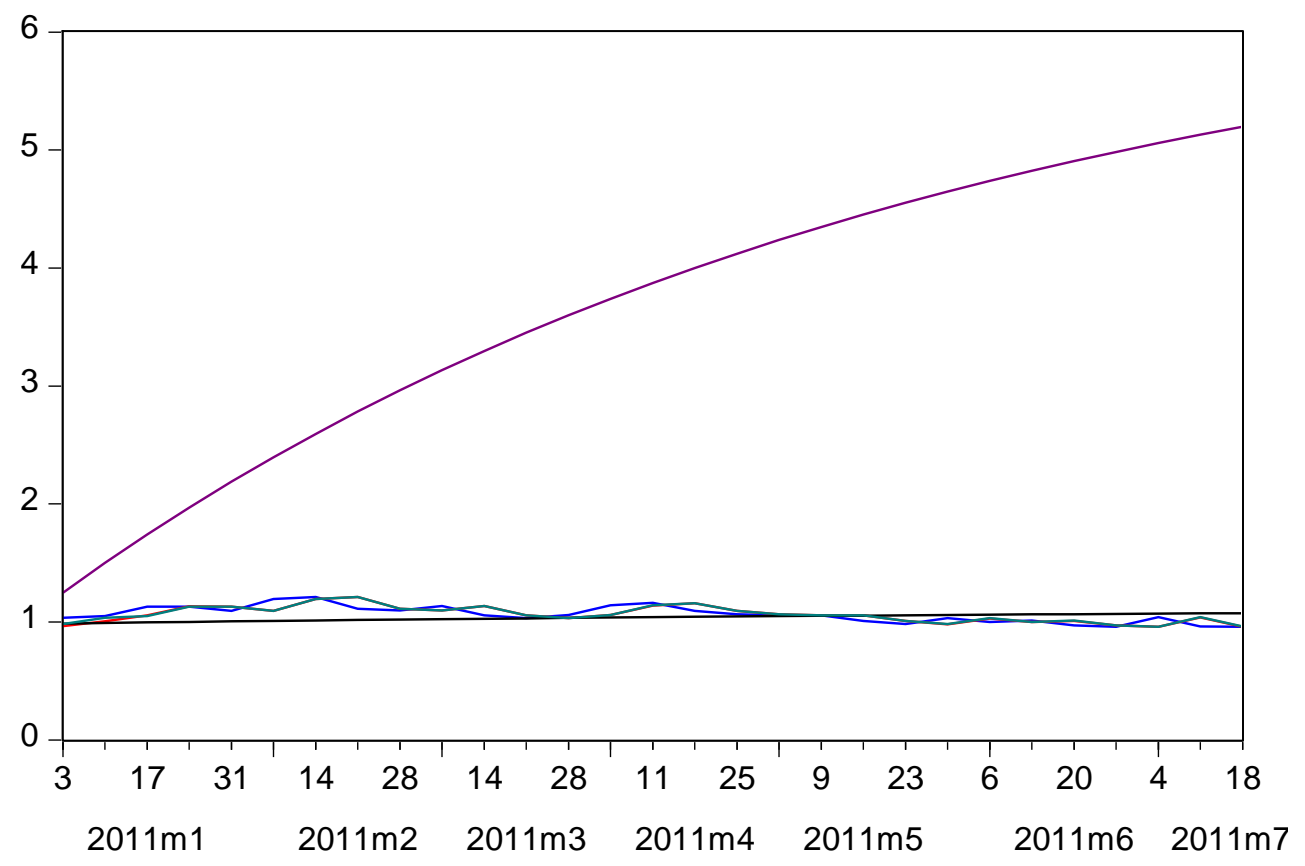

\begin{tabular}{|r|}
\hline JAP10YS Actual \\
JAP10YS ARIMA JAP10YS ARFIMA \\
JAP10YS Merton \\
\end{tabular}

Japanese 10-Year Treasury Yield Spreads
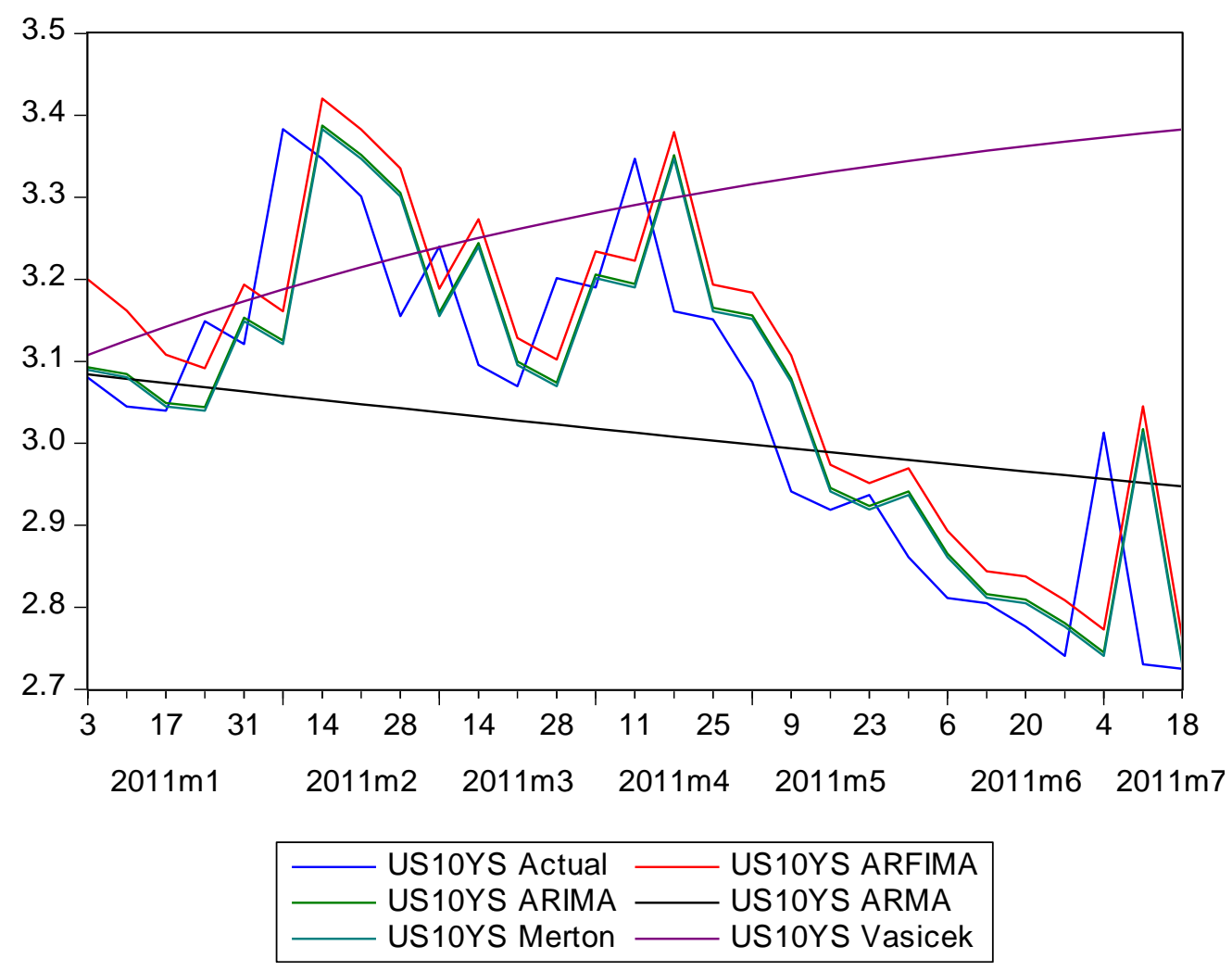

US 10-Year Treasury Yield Spreads 
Table 1: Summary Data Statistics for Spread Levels

\begin{tabular}{|c|c|c|c|c|c|c|c|c|c|c|}
\hline \multicolumn{11}{|c|}{ Panel A - UK Spreads } \\
\hline & Obs. & Mean & Variance & SD & $\rho(1)$ & $\rho(2)$ & $\rho(3)$ & $\rho(4)$ & $\rho(5)$ & $\rho(6)$ \\
\hline \multirow[t]{2}{*}{ UK15YS } & 156 & 0.397 & 2.712 & 1.647 & $3.541 * * *$ & $6.008 * *$ & $15.524^{*}$ & $15.685^{*}$ & $15.695^{*}$ & $16.282^{* *}$ \\
\hline & & & & & $(0.060)$ & $(0.050)$ & $(0.001)$ & $(0.003)$ & $(0.008)$ & $(0.012)$ \\
\hline \multirow[t]{2}{*}{ UK20YS } & 156 & 0.331 & 3.099 & 1.760 & $5.261 * *$ & $9.779 *$ & $20.295^{*}$ & $20.364 *$ & $20.395^{*}$ & $20.537 *$ \\
\hline & & & & & $(0.022)$ & $(0.008)$ & $(0.000)$ & $(0.000)$ & $(0.001)$ & $(0.002)$ \\
\hline \multirow[t]{2}{*}{ UK25YS } & 156 & 0.233 & 3.305 & 1.818 & 7.179* & $14.811^{*}$ & $25.542^{*}$ & $25.714^{*}$ & $25.730 *$ & $25.772 *$ \\
\hline & & & & & $(0.007)$ & $(0.001)$ & & $(0.000)$ & $(0.000)$ & $(0.000)$ \\
\hline
\end{tabular}

\begin{tabular}{|c|c|c|c|c|c|c|c|c|c|c|}
\hline \multicolumn{11}{|c|}{ Panel B - International Spreads } \\
\hline & Obs. & Mean & Variance & SD & $\rho(1)$ & $\rho(2)$ & $\rho(3)$ & $\rho(4)$ & $\rho(5)$ & $\rho(6)$ \\
\hline GER10YS & 574 & 1.202 & 0.857 & 0.926 & $\begin{array}{l}3.728 * * * \\
(0.053)\end{array}$ & $\begin{array}{l}3.979 \\
(0.137)\end{array}$ & $\begin{array}{l}5.507 \\
(0.138)\end{array}$ & $\begin{array}{l}6.541 \\
(0.162)\end{array}$ & $\begin{array}{l}6.906 \\
(0.228)\end{array}$ & $\begin{array}{l}7.044 \\
(0.317)\end{array}$ \\
\hline JAP10YS & 574 & 1.178 & 0.099 & 0.315 & $\begin{array}{l}0.514 \\
(0.473)\end{array}$ & $\begin{array}{l}6.986 * * \\
(0.030)\end{array}$ & $\begin{array}{l}10.226 * * \\
(0.017)\end{array}$ & $\begin{array}{l}-0.075 \\
(0.161)\end{array}$ & $\begin{array}{l}28.042^{*} \\
(0.000)\end{array}$ & $\begin{array}{l}28.043^{*} \\
(0.000)\end{array}$ \\
\hline US10YS & 574 & 1.448 & 2.264 & 1.505 & $\begin{array}{l}25.088^{*} \\
(0.000)\end{array}$ & $\begin{array}{l}26.866^{*} \\
(0.000)\end{array}$ & $\begin{array}{l}26.899 * \\
(0.000)\end{array}$ & $\begin{array}{l}32.003 * \\
(0.000)\end{array}$ & $\begin{array}{l}39.823 * \\
(0.000)\end{array}$ & $\begin{array}{l}41.772 * \\
(0.000)\end{array}$ \\
\hline
\end{tabular}

Note: This table provides the descriptive statistics for the Treasury yield spreads for the period between January 1998 and December 2010 , for the UK spreads, and January 2000 and December 2010, for the international spreads. The UK spreads are calculated as the spread between the 1-month yield and 15-year, 20-year and 25-year yields on UK Treasuries, denoted UK15YS, UK20YS, UK25YS, respectively. The international spreads are calculated as the spread between the 1-month interbank rate and 10-year yield on German, Japanese and US Treasuries, denoted GER10YS, JAP10YS and US10YS, respectively. Figures in parentheses denote the respective $p$-values and $(*, * *, * * *)$ denote a coefficient that is significant at the $1 \%, 5 \%$ and $10 \%$ levels, respectively. 
Table 2: Summary Data Statistics for First-Differences of Spreads

\begin{tabular}{|c|c|c|c|c|c|c|c|c|c|c|}
\hline \multicolumn{11}{|c|}{ Panel A - UK Spreads } \\
\hline & Obs. & Mean & Variance & SD & $\rho(1)$ & $\rho(2)$ & $\rho(3)$ & $\rho(4)$ & $\rho(5)$ & $\rho(6)$ \\
\hline \multirow[t]{2}{*}{ UK15YS } & 155 & 0.031 & 0.080 & 0.282 & 0.122 & 0.815 & $9.920 * *$ & $10.779 * *$ & $10.811^{* * *}$ & $11.552^{* * *}$ \\
\hline & & & & & $(0.727)$ & $(0.665)$ & (0.019) & $(0.029)$ & $(0.055)$ & $(0.073)$ \\
\hline \multirow[t]{2}{*}{ UK2OYS } & 155 & 0.032 & 0.082 & 0.286 & 0.247 & 1.642 & $11.064 * *$ & $12.063 * *$ & $12.090 * *$ & $12.299 * * *$ \\
\hline & & & & & $(0.619)$ & $(0.440)$ & $(0.011)$ & $(0.017)$ & $(0.034)$ & $(0.056)$ \\
\hline \multirow[t]{2}{*}{ UK25YS } & 155 & 0.033 & 0.081 & 0.285 & 0.460 & 3.201 & $11.109 * *$ & $11.223 * *$ & $11.300 * *$ & $11.444^{* * *}$ \\
\hline & & & & & $(0.498)$ & $(0.202)$ & $(0.011)$ & $(0.024)$ & $(0.046)$ & $(0.076)$ \\
\hline
\end{tabular}

\begin{tabular}{|c|c|c|c|c|c|c|c|c|c|c|}
\hline \multicolumn{11}{|c|}{ Panel B - International Spreads } \\
\hline & Obs. & Mean & Variance & SD & $\rho(1)$ & $\rho(2)$ & $\rho(3)$ & $\rho(4)$ & $\rho(5)$ & $\rho(6)$ \\
\hline \multirow[t]{2}{*}{ GER10YS } & 573 & 0.000 & 0.015 & 0.121 & 0.001 & 0.584 & 2.110 & 3.083 & 3.643 & 3.777 \\
\hline & & & & & $(0.981)$ & $(0.747)$ & $(0.550)$ & $(0.544)$ & $(0.602)$ & $(0.707)$ \\
\hline \multirow[t]{2}{*}{ JAP10YS } & 573 & -0.001 & 0.006 & 0.077 & 0.005 & $6.992 * *$ & $10.512^{* *}$ & $25.028 *$ & $27.313^{*}$ & $27.316^{*}$ \\
\hline & & & & & $(0.942)$ & $(0.030)$ & $(0.015)$ & $(0.000)$ & $(0.000)$ & $(0.000)$ \\
\hline \multirow[t]{2}{*}{ US10YS } & 573 & 0.004 & 0.030 & 0.174 & 0.006 & 0.162 & 0.162 & 3.470 & 8.568 & 9.869 \\
\hline & & & & & (0.939) & $(0.922)$ & $(0.983)$ & $(0.483)$ & $(0.128)$ & $(0.130)$ \\
\hline
\end{tabular}

Note: This table provides the descriptive statistics for the change in the Treasury yield spreads for the period between January 1998 and December 2010 , for the UK spreads, and January 2000 and December 2010, for the international spreads. The UK spreads are calculated as the spread between the 1-month yield and 15-year, 20-year and 25-year yields on UK Treasuries, denoted UK15YS, UK20YS, UK25YS, respectively. The international spreads are calculated as the spread between the 1-month interbank rate and 10-year yield on German, Japanese and US Treasuries, denoted GER10YS, JAP10YS and US10YS, respectively. Figures in parentheses denote the respective $p$-values and $(*, * *, * * *)$ denote a coefficient that is significant at the $1 \%, 5 \%$ and $10 \%$ levels, respectively. 
Table 3: Unit Root Tests on Spread Levels

\begin{tabular}{llll}
\hline Panel A - UK Spreads & & & \\
& UK15YS & US20YS & UK25YS \\
\hline Augmented Dickey-Fuller Test Statistic & -1.407 & -1.425 & -1.482 \\
& $(0.578)$ & $(0.569)$ & $(0.540)$ \\
Phillips-Perron Test Statistic & -0.917 & -0.844 & -0.858 \\
& $(0.781)$ & $(0.804)$ & $(0.799)$ \\
KPSS Test Statistic & $0.670^{* *}$ & $0.680^{* *}$ & $0.674^{* *}$ \\
& & & \\
\hline Panel B - International Spreads & & & \\
& GER10YS & JAP10YS & US10YS \\
\hline Augmented Dickey-Fuller Test Statistic & -1.554 & $-2.881^{* *}$ & -1.563 \\
& $(0.506)$ & $(0.048)$ & $(0.501)$ \\
Phillips-Perron Test Statistic & -1.699 & $-3.003^{* *}$ & -1.388 \\
& $(0.432)$ & $(0.035)$ & $(0.589)$ \\
KPSS Test Statistic & 0.239 & $0.657^{* *}$ & 0.322 \\
\end{tabular}

Note 1: This table presents the results of the Augmented Dickey-Fuller (Dickey and Fuller (1981)), PhillipsPerron (Phillips and Perron (1988)) and KPSS (Kwiatkowski, et al. (1992)) unit root tests on the Treasury yield spreads for the period between January 1998 and December 2010, for the UK spreads, and January 2000 and December 2010, for the international spreads. The UK spreads are calculated as the spread between the 1-month yield and 15-year, 20-year and 25-year yields on UK Treasuries, denoted UK15YS, UK20YS, UK25YS, respectively. The international spreads are calculated as the spread between the 1-month interbank rate and 10year yield on German, Japanese and US Treasuries, denoted GER10YS, JAP10YS and US10YS, respectively. Figures in parentheses denote the respective $p$-values, critical values for the KPSS test are 1\%: 0.739, 5\%: 0.463 and 10\%: 0.347; and $(*, * *, * * *)$ denote a test coefficient that is significant at the $1 \%, 5 \%$ and $10 \%$ levels, respectively.

Note 2: The results of the same unit root tests on the changes in interest rate spreads (the first-difference of the series) are not presented for reasons of brevity, but are available upon request. 
Table 4: Continuous Time Results for the UK and International Spreads

\begin{tabular}{|c|c|c|c|}
\hline \multicolumn{4}{|c|}{ Panel A - UK Spreads } \\
\hline & UK15YS & UK20YS & UK25YS \\
\hline \multicolumn{4}{|c|}{ Merton } \\
\hline \multirow[t]{2}{*}{$\alpha$} & $-0.0008^{*}$ & $-0.0008^{*}$ & $-0.0008 *$ \\
\hline & $(0.0002)$ & $(0.0002)$ & $(0.0002)$ \\
\hline \multirow[t]{2}{*}{$\sigma^{2}$} & 0.00001 & 0.00001 & 0.00001 \\
\hline & $(0.00001)$ & $(0.00001)$ & $(0.00001)$ \\
\hline \multicolumn{4}{|c|}{ Vasicek } \\
\hline \multirow[t]{2}{*}{$\alpha$} & 0.0003 & 0.0003 & 0.0003 \\
\hline & $(0.0002)$ & $(0.0002)$ & $(0.0002)$ \\
\hline \multirow[t]{2}{*}{$\beta$} & -0.0098 & -0.0067 & -0.0053 \\
\hline & $(0.0157)$ & $(0.0144)$ & $(0.0141)$ \\
\hline \multirow[t]{2}{*}{$\sigma^{2}$} & 0.00001 & 0.00001 & 0.00001 \\
\hline & $(0.00001)$ & $(0.00001)$ & $(0.00001)$ \\
\hline \multicolumn{4}{|c|}{ Panel B - International Spreads } \\
\hline & GER10YS & JAP10YS & US10YS \\
\hline \multicolumn{4}{|c|}{ Merton } \\
\hline \multirow[t]{2}{*}{$\alpha$} & 0.00001 & $-0.0001 * *$ & 0.00004 \\
\hline & $(0.00005)$ & $(0.00004)$ & $(0.00007)$ \\
\hline \multirow[t]{2}{*}{$\sigma^{2}$} & 0.000001 & 0.00001 & 0.00001 \\
\hline & $(0.00001)$ & $(0.00001)$ & $(0.00001)$ \\
\hline \multicolumn{4}{|c|}{ Vasicek } \\
\hline \multirow[t]{2}{*}{$\alpha$} & $0.0020^{*}$ & $0.0032 *$ & $0.0017^{*}$ \\
\hline & $(0.0002)$ & $(0.0004)$ & $(0.0002)$ \\
\hline \multirow[t]{2}{*}{$\beta$} & $-0.0234 * * *$ & -0.0489 & $-0.0489 *$ \\
\hline & $(0.0137)$ & $(0.0393)$ & $(0.0087)$ \\
\hline \multirow[t]{2}{*}{$\sigma^{2}$} & 0.00001 & 0.00001 & 0.00001 \\
\hline & $(0.00001)$ & $(0.00001)$ & $(0.00001)$ \\
\hline
\end{tabular}

Note: This table provides the results for the Merton and Vasicek models of the Treasury yield spreads for the period between January 1998 and December 2010, for the UK spreads, and January 2000 and December 2010, for the international spreads. The UK spreads are calculated as the spread between the 1-month yield and 15year, 20-year and 25-year yields on UK Treasuries, denoted UK15YS, UK20YS, UK25YS, respectively. The international spreads are calculated as the spread between the 1-month interbank rate and 10-year yield on German, Japanese and US Treasuries, denoted GER10YS, JAP10YS and US10YS, respectively. Figures in parentheses denote the respective standard errors. *,**,*** denote a coefficient that is significant at the $1 \%$, $5 \%$ and $10 \%$ levels, respectively. 
Table 5: ARMA Results for the UK and International Spreads

\begin{tabular}{|c|c|c|c|}
\hline \multicolumn{4}{|c|}{ Panel A - UK Spreads } \\
\hline & UK15YS & UK20YS & UK25YS \\
\hline \multirow[t]{2}{*}{$\alpha$} & 5.509 & 9.118 & 13.717 \\
\hline & $(12.482)$ & $(32.628)$ & $(71.844)$ \\
\hline \multirow[t]{2}{*}{$\phi(1)$} & $0.994 *$ & $0.996 *$ & $0.998 *$ \\
\hline & $(0.014)$ & $(0.013)$ & $(0.013)$ \\
\hline Log-Likelihood & -23.157 & -25.109 & -24.910 \\
\hline AIC & -2.526 & -2.501 & -2.503 \\
\hline SBIC & -2.461 & -2.436 & -2.438 \\
\hline \multicolumn{4}{|c|}{ Panel B - International Spreads } \\
\hline & GER10YS & JAP10YS & US10YS \\
\hline \multirow[t]{2}{*}{$\alpha$} & $1.205^{* *}$ & $1.146^{*}$ & 2.150 \\
\hline & $(0.595)$ & $(0.105)$ & $(1.377)$ \\
\hline \multirow[t]{2}{*}{$\phi(1)$} & $0.992 *$ & $0.970 *$ & $0.994 *$ \\
\hline & $(0.005)$ & $(0.010)$ & $(0.005)$ \\
\hline Log-Likelihood & 399.892 & 664.794 & 191.132 \\
\hline AIC & -4.230 & -5.155 & -3.502 \\
\hline SBIC & -4.208 & -5.133 & -3.479 \\
\hline \multicolumn{4}{|c|}{$\begin{array}{l}\text { Note: This table provides the results for the ARMA model of the Treasury yield spreads for the period } \\
\text { between January } 1998 \text { and December } 2010 \text {, for the UK spreads, and January } 2000 \text { and December } 2010 \text {, for the } \\
\text { international spreads. The UK spreads are calculated as the spread between the } 1 \text {-month yield and } 15 \text {-year, 20- } \\
\text { year and } 25 \text {-year yields on UK Treasuries, denoted UK15YS, UK20YS, UK25YS, respectively. The } \\
\text { international spreads are calculated as the spread between the 1-month interbank rate and } 10 \text {-year yield on } \\
\text { German, Japanese and US Treasuries, denoted GER10YS, JAP10YS and US10YS, respectively. Figures in } \\
\text { parentheses denote the respective standard errors and }(*, * *, * * *) \text { denote a coefficient that is significant at the } \\
1 \%, 5 \% \text { and } 10 \% \text { levels, respectively. }\end{array}$} \\
\hline
\end{tabular}




\begin{tabular}{|c|c|c|c|}
\hline \multicolumn{4}{|c|}{ Panel A - UK Spreads } \\
\hline & UK15YS & UK20YS & UK25YS \\
\hline \multirow[t]{2}{*}{$\alpha$} & 0.034 & 0.033 & 0.037 \\
\hline & $(0.035)$ & $(0.028)$ & $(0.040)$ \\
\hline \multirow[t]{2}{*}{$\rho(1)$} & $0.742^{*}$ & $0.183^{* *}$ & $0.748 *$ \\
\hline & $(0.210)$ & $(0.080)$ & $(0.157)$ \\
\hline \multirow[t]{2}{*}{$\theta(1)$} & $-0.599 * *$ & ----- & $-0.551^{*}$ \\
\hline & $(0.252)$ & $(----)$ & $(0.198)$ \\
\hline Log-Likelihood & -20.020 & -22.812 & -18.309 \\
\hline AIC & -2.558 & -2.529 & -2.580 \\
\hline SBIC & -2.460 & -2.463 & -2.482 \\
\hline \multicolumn{4}{|c|}{ Panel B - International Spreads } \\
\hline & GER10YS & JAP10YS & US10YS \\
\hline \multirow[t]{2}{*}{$\alpha$} & 0.000 & -0.001 & 0.004 \\
\hline & $(0.005)$ & $(0.003)$ & $(0.009)$ \\
\hline \multirow[t]{2}{*}{$\rho(1)$} & ----- & 0.270 & $0.208 *$ \\
\hline & $(----)$ & $(0.558)$ & $(0.041)$ \\
\hline \multirow[t]{2}{*}{$\theta(1)$} & $0.085^{* *}$ & -0.226 & ----- \\
\hline & $(0.042)$ & $(0.565)$ & $(----)$ \\
\hline Log-Likelihood & 400.635 & 659.872 & 202.292 \\
\hline AIC & -4.233 & -5.140 & -3.542 \\
\hline SBIC & -4.211 & -5.107 & -3.519 \\
\hline
\end{tabular}

Note 1: This table provides the results for the ARIMA model of the Treasury yield spreads for the period between January 1998 and December 2010, for the UK spreads, and January 2000 and December 2010, for the international spreads. The UK spreads are calculated as the spread between the 1-month yield and 15-year, 20year and 25-year yields on UK Treasuries, denoted UK15YS, UK20YS, UK25YS, respectively. The international spreads are calculated as the spread between the 1-month interbank rate and 10-year yield on German, Japanese and US Treasuries, denoted GER10YS, JAP10YS and US10YS, respectively. Figures in parentheses denote the respective standard errors and $(*, * *, * *)$ denote a coefficient that is significant at the $1 \%, 5 \%$ and $10 \%$ levels, respectively.

Note 2: The ARIMA models run on the Japanese spreads were not found to be significant, but are presented for convenience and consistency. 
Table 7: ARFIMA Results for the UK and International Spreads

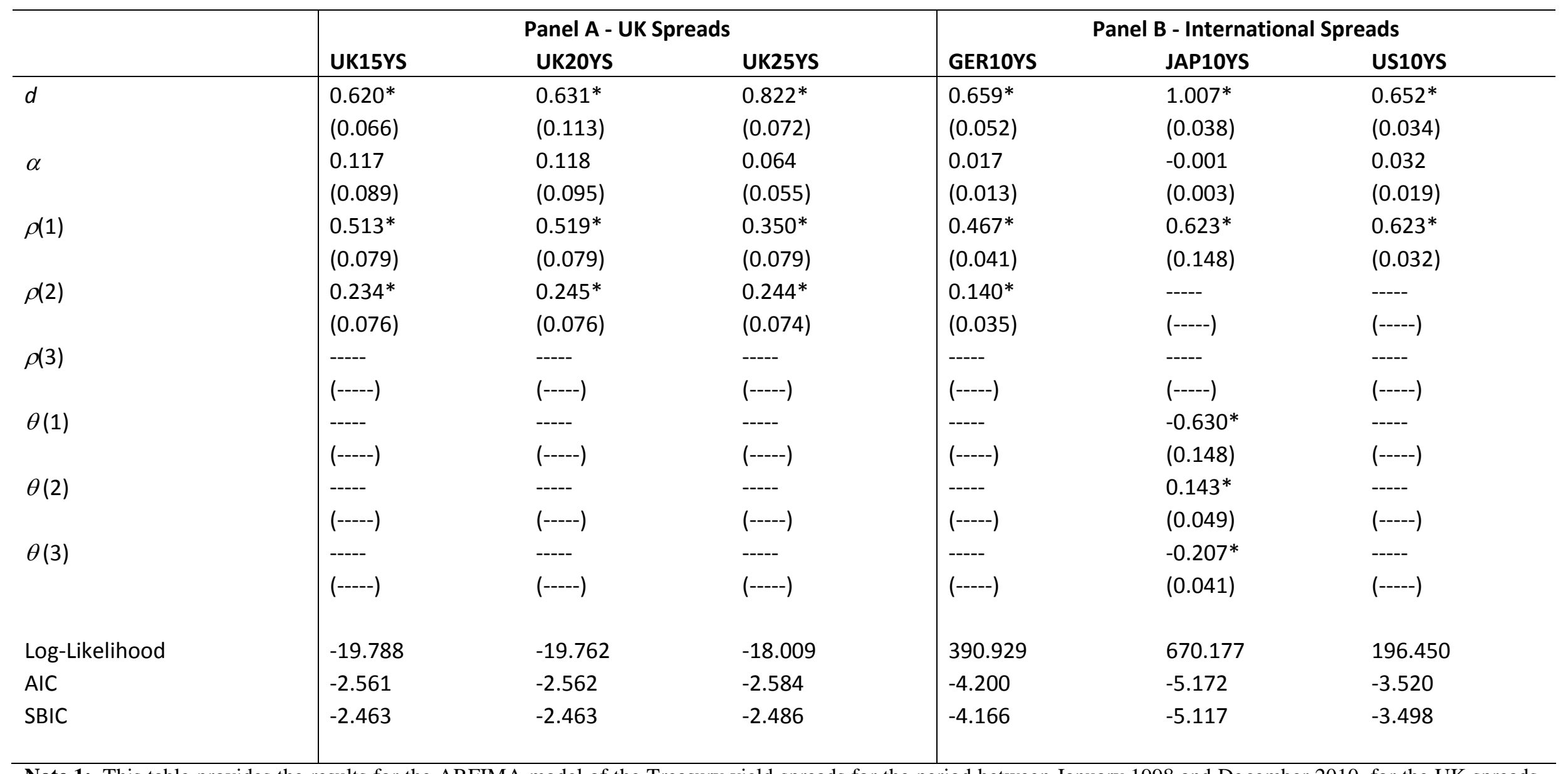

Note 1: This table provides the results for the ARFIMA model of the Treasury yield spreads for the period between January 1998 and December 2010, for the UK spreads, and January 2000 and December 2010, for the international spreads. The UK spreads are calculated as the spread between the 1-month yield and 15-year, 20-year and 25-year yields on UK Treasuries, denoted UK15YS, UK20YS, UK25YS, respectively. The international spreads are calculated as the spread between the 1-month interbank rate and 10-year yield on German, Japanese and US Treasuries, denoted GER10YS, JAP10YS and US10YS, respectively. Figures in parentheses denote the respective standard errors and $(*, * *, * * *)$ denote a coefficient that is significant at the $1 \%, 5 \%$ and $10 \%$ levels, respectively. 
Table 8: Forecast Metrics for the UK and International Spreads

\begin{tabular}{lcccccc}
\hline \multicolumn{2}{l}{ Panel A - Mean of Forecast Errors } & & & & & \\
& UK15YS & UK20YS & UK25YS & GER10YS & JAP10YS & US10YS \\
\hline ARMA Model & 0.2299 & 0.1864 & 0.1725 & -0.0673 & 0.0263 & 0.0347 \\
ARIMA Model & -0.0225 & -0.0256 & -0.0198 & -0.0370 & N/A & -0.0169 \\
ARFIMA Model & -0.1779 & -0.1612 & -0.0426 & -0.0622 & 0.0009 & -0.0523 \\
Merton Model & 0.0183 & 0.0108 & 0.0083 & -0.0364 & -0.0007 & -0.0126 \\
Vasicek Model & 0.2268 & 0.1826 & 0.1675 & -1.9623 & -2.5807 & -0.2260
\end{tabular}

\begin{tabular}{lcccccc}
\hline \multicolumn{2}{l}{ Panel B - Variance of Forecast Errors } & & & & & \\
& UK15YS & UK20YS & UK25YS & GER10YS & JAP10YS & US10YS \\
\hline ARMA Model & 0.0085 & 0.0127 & 0.0166 & 0.1047 & 0.0079 & 0.0279 \\
ARIMA Model & 0.0516 & 0.0434 & 0.0476 & 0.0122 & N/A & 0.0142 \\
ARFIMA Model & 0.0319 & 0.0336 & 0.0450 & 0.0117 & 0.0027 & 0.0143 \\
Merton Model & 0.0390 & 0.0387 & 0.0430 & 0.0122 & 0.0026 & 0.0142 \\
Vasicek Model & 0.0087 & 0.0131 & 0.0173 & 1.4880 & 1.5194 & 0.0649
\end{tabular}

\begin{tabular}{lcccccc}
\hline \multicolumn{2}{l}{ Panel C - Mean Absolute Percentage Error } & & & & \\
& UK15YS & UK20YS & UK25YS & GER10YS & JAP10YS & US10YS \\
\hline ARMA Model & $6.060 \%$ & $4.690 \%$ & $4.317 \%$ & $15.093 \%$ & $7.075 \%$ & $4.611 \%$ \\
ARIMA Model & $4.450 \%$ & $4.128 \%$ & $4.263 \%$ & $4.511 \%$ & N/A & $2.812 \%$ \\
ARFIMA Model & $5.686 \%$ & $5.425 \%$ & $4.432 \%$ & $5.012 \%$ & $3.916 \%$ & $3.518 \%$ \\
Merton Model & $3.394 \%$ & $3.426 \%$ & $3.703 \%$ & $4.496 \%$ & $3.780 \%$ & $2.737 \%$ \\
Vasicek Model & $5.977 \%$ & $4.593 \%$ & $4.295 \%$ & $110.552 \%$ & $248.701 \%$ & $8.948 \%$
\end{tabular}

\begin{tabular}{lcccccc}
\hline \multicolumn{3}{l}{ Panel D - Root Mean Squared Error } & & & & \\
& UK15YS & UK20YS & UK25YS & GER10YS & JAP10YS & US10YS \\
\hline ARMA Model & 0.2433 & 0.2103 & 0.2054 & 0.3249 & 0.0913 & 0.1678 \\
ARIMA Model & 0.1980 & 0.1822 & 0.1899 & 0.1147 & N/A & 0.1183 \\
ARFIMA Model & 0.2357 & 0.2263 & 0.1885 & 0.1233 & 0.0514 & 0.1285 \\
Merton Model & 0.1719 & 0.1706 & 0.1797 & 0.1146 & 0.0505 & 0.1178 \\
Vasicek Model & 0.2408 & 0.2077 & 0.2025 & 2.2995 & 2.8508 & 0.3372
\end{tabular}

\begin{tabular}{lcccccc}
\hline \multicolumn{7}{l}{ Panel E - Percentage Correct Direction Predicted } \\
& UK15YS & UK20YS & UK25YS & GER10YS & JAP10YS & US10YS \\
\hline ARMA Model & $50.000 \%$ & $25.000 \%$ & $25.000 \%$ & $65.517 \%$ & $44.828 \%$ & $75.862 \%$ \\
ARIMA Model & $25.000 \%$ & $75.000 \%$ & $75.000 \%$ & $48.276 \%$ & N/A & $48.276 \%$ \\
ARFIMA Model & $50.000 \%$ & $75.000 \%$ & $75.000 \%$ & $48.276 \%$ & $44.828 \%$ & $48.276 \%$ \\
Merton Model & $0.000 \%$ & $50.000 \%$ & $50.000 \%$ & $48.276 \%$ & $41.379 \%$ & $48.276 \%$ \\
Vasicek Model & $50.000 \%$ & $25.000 \%$ & $25.000 \%$ & $34.483 \%$ & $44.828 \%$ & $24.138 \%$
\end{tabular}

Note 1: This table provides the forecast metrics for the various models employed to forecast the Treasury yield spreads. The forecast period extended from January 2011 till April 2011, for the UK spreads, and from 3 January 2011 till 18 July 2011, for the international spreads.

Note 2: Forecast metrics are not provided for the ARIMA model in the case of the Japanese spread as the results for this model were found to be insignificant in the in-sample period estimations. 